\author{
Stanislava D. Radosavljević* \\ Univerzitet u Beogradu \\ Filološki fakultet
}

https://doi.org/10.18485/analiff.2018.30.2.6

821.111(73).09-2:792.091“1958/2017““

(497.113 Нови Сад)

Originalni naučni rad

Primljen: 20.07.2018.

Prihvaćen: 21.09.2018.

\title{
SAVREMENA AMERIČKA DRAMA NA NOVOSADSKIM SCENAMA OD 1958. DO 2017. GODINE
}

\begin{abstract}
U našem radu, istražićemo period od 1958. kada je izvedena prva drama (Tetovirana ruža Tenesi Vilijamsa) pa sve do 2017. godine. Istražićemo američke drame na novosadskim pozornicama. Akcenat će biti na dva novosadska pozorišta, Srpskom narodnom pozorištu i Novosadskom pozorištu, dok se posebna pažnja neće posvetiti Pozorištu mladih, osim gostovanja koja će biti pomenuta u ovom radu. Od svih modernih američkih pisaca, najčešće su izvođena dela: Judžina O’Nila, Tenesi Vilijamsa, Artura Milera, Sema Šeparda, Edvarda Olbija i Dejvida Mameta. Glavni cilj ovog istraživanja biće recepcija njihovih dela na novosadsku publiku. Pokazaćemo kada, kako i pod kojim okolnostima su komadi navedenih pisaca prikazani i kakav su uticaj imali kod publike, zašto su neke drame i dalje aktuelne, a zašto se druge više ne prikazuju. U izradi rada koristićemo pozorišne godišnjake, novinske članke i kritčke osvrte, pozorišne anale i arhiv Sterijinog pozorja.
\end{abstract}

Ključne reči: Američka drama, novosadska pozorišta, Judžin O’Nil, Tenesi Vilijams, Artur Miler, Sem Šepard, Edvard Olbi, Dejvid Mamet

\section{UVOD}

Američka drama doživela je procvat u XX veku. Iako kroz istoriju nije imala velika imena, kao što je to slučaj Engleske sa Šekspirom, Francuske sa Molijerom, Španije sa Kalderonom de la Barkom, Nemačke sa Geteom, taj će nedostatak dobrim delom ispraviti dela Judžina O’Nila',

* Studentkinja Doktorskih studija književnosti; Filološki fakultet Univerziteta u Beogradu. E-mail: stasha93@live.com.

1 Judžin Gledstoun O’Nil (Eugene Gladstone O’Neill, Njujork, 16. oktobar 1888. Boston, 27. novembar 1953.) američki dramski pisac, dobitnik Nobelove nagrade za književnost 1936. godine. Njegove drame su među prvima koje su unele reali- 
Tenesi Vilijamsa ${ }^{2}$, Artura Milera ${ }^{3}$ i drugih autora, koji i danas svojim komadima privlače pozorišnu publiku širom sveta, ali i kod nas.

Između dva svetska rata, američki pisci nisu bili izvođeni na našim scenama; jedini izuzetak je bila drama Judžina O’Nila Ana Kristi ${ }^{4}$. Američki dramski pisci su imali značajnu ulogu u vreme jugoslovenskog socijalizma, posebno nakon raskida sa politikom takozvanog realnog socijalizma u kulturi, jer je prvih 10-ak godina nakon II svetskog rata u zvaničnoj kulturi vladalo poprilično antiameričko raspoloženje. Pojavom Tenesi Vilijamsa i Artura Milera u Beogradskom dramskom pozorištu polovinom XX veka, najavljeno je otvaranje prema zapadu ${ }^{5}$. Dva pomenuta dramatičara su utrli put američkom realističkom pozorištu širom sveta, ali i kod nas. Njih sledi Edvard Olbi ${ }^{6}$, kao svojevrsni spoj Vilijamsa i Milera, društveni kritičar i psihoanalitičar, dokaz da se realizam najbolje manifestuje u američkoj drami i to u takozvanim dramama porodičnog kruga.

Nakon mjuzikla Kosa (1967. godine) jugoslovensko pozorište i pisci kreću novim pravcima. Javlja se fenomen pobune, koji je prisutan u najrazličitijim formama i temama. Ali, šta god da se istorijski dešavalo, na kraju, američki dramski pisci su se uvek vraćali realizmu. Najavangardniji

zam u američko pozorište

2 Tenesi Vilijams (Thomas Lanier Williams III, Kolumbus, 26. mart 1911. - Njujork, 25. februar 1983.) američki dramski pisac i jedan od najznačajnijih dramskih pisaca XX veka. Dobitnik dve Pulicerove nagrade za komad Tramvaj zvani želja, 1948. godine, i za dramu Mačka na usijanom limenom krovu, 1955. godine. Njegove drame Staklena menažerija iz 1945. i Noć iguane iz 1961. godine, osvojile su nagradu Njujorškog udruženja dramskih kritičara. Drama Tetovirana ruža 1952. godine osvojila je nagradu Toni za najbolji pozorišni komad.

3 Artur Ašer Miler (Arthur Asher Miller, Njujork. 17. oktobar 1915. - Roksburi, 10. februar 2005.) američki dramski pisac, dobio je Pulicerovu nagradu za dramu 1949. godine. Pored drama, pisao je i scenarije za filmove. Drama Smrt trgovačkog putnika se svrstava među najbolje američke drame napisane u XX veku.

4 Vidi: Ćirilov, Jovan (prir.). Pre i posle Kose. Savremena američka drama. Beograd: Zepter Book World, 2002.

5 Vidi: Vučetić, Radina. Koka-kola socijalizam. Amerikanizacija jugoslovenske popularne kulture šezdesetih godina XX veka. Beograd: Službeni glasnik, 2012.

6 Edvard Olbi (Edward Albee, Vašington. 12. mart 1928. - Montauk, 16. septembar 2016.) američki dramski pisac, dobitnik tri Pulicerove nagrade za drame Delikatna ravnoteža 1967. godine, Primorje 1975. godine i Tri visoke žene 1994. godine. Takođe, dobitnik dve Toni nagrade za drame, Ko se boji Virdžinije Vulf? 1963. godine i Koza ili ko je Silvija, 2002. godine 
pisac koji će biti pomenut u ovom tekstu je Sem Šepard7 ${ }^{7}$ koji je tragao za smislom pozorišta u najekstremnijim pravcima. Posle eksperimentalne faze, u poznim godinama njegov stil pisanja sve više podseća na začetnika američke drame Judžina O’Nila, zatim i na Artura Milera. Poslednji, još uvek živ predstavnik kritičke dramske misli je Dejvid Mamet ${ }^{8}$. Njegov realizam je svestan svega što se desilo pre njega i njegovih prethodnika, ali on iznosi svoju kritiku i misao koja se odnosi na Ameriku. Kasnije svetlo pozornice ugledaće i drame manjina koje su se izborile za svoje pravo glasa. Napredak u svetu, nauci i tehnologiji je pogodovao civilizaciji, ali ne i dramskoj književnosti. Tako Jovan Ćirilov kaže: „Vreme koje živimo na početku XXI veka, ako je suditi po dramama u Americi, svakako nije velika epoha“ (Ćirilov, 2002: 6). Možemo dodati da su se toga stava držali i u novosadskim pozorištima, ako pogledamo broj izvođenja američkih drama na scenama tih teatara.

\section{NOVOSADSKA POZORIŠTA}

\section{1. Srpsko narodno pozorište}

Srpsko narodno pozorište je osnovano 1861. godine. Prvi glumci, među kojima su bili i Dimitrije Ružić, Draginja Ružić, Laza Telečki, Draga Spasić, Pera Dobrinović ${ }^{9}$ su bili i misionari koji su širili kulturu sa pozornice među narodom. Od 1956. se u pozorištu održava i Sterijino pozorje ${ }^{10}$. Prvi američki autor koji je premijerno prikazan na daskama SNP-a, bio je

$7 \quad$ Sem Šepard (Samuel Shepard Rogers III, Fort Šeridan. 5. novembar 1943. - Midvej, 27. jul 2017. godine) američki dramski pisac. Dobitnik je Pulicerove nagrade 1979. godine, kao i mnogih drugih pozorišnih i fimskih nagrada. Takođe je pisao scenarije za filmove (Lud od ljubavi, 1985. godine).

8 Dejvid Mamet (David Alan Mamet, Čikago. 30. novembar 1947.) američki dramski pisac, dobio Pulicerovu nagradu za dramu 1984. godine. I dalje se aktivno bavi pisanjem. Osim drama, piše i scenarije i knjige vezane za film i pozorište.

9 Petar-Pera Dobrinović (Beograd, 11. jun 1853. - Novi Sad, 21. decembar 1923.godine) glumac i reditelj u Srpskom narodnom pozorištu i Narodnom pozorištu u Beogradu.

10 Sterijino pozorje je festival nacionalne drame i pozorišta takmičarskog karaktera, osnovan 1956. godine, povodom obeležavanja 150-godišnjice rođenja i 100-godišnjice smrti komediografa Jovana Sterije Popovića. Na njemu učestvuju pozorišta iz zemlje i inostranstva sa predstavama rađenim po tekstovima domaćih autora. 
Tenesi Vilijams, 1958. godine, sa dramom Tetovirana ruža. Tokom 60-ih i 70-ih godina XX veka, američki dramski pisci nisu bili nepoznanica na scenama novosadskih pozorišta, pa čak ni tokom ratnih 90-ih godina. Nažalost, posle 1998. godine scensko prikazivanje američkog sna ne zanima novosadske teatarske poslenike, a izgleda ni domaću publiku.

\section{2. Novosadsko pozorište}

Novosadsko pozorište (Ujvideki Szinhaz) osnovano je 1974. godine, kako bi se očuvao kulturni identitet mađarske nacionalne zajednice u Vojvodini. Tokom godina je postalo mesto okupljanja svih građana, ne samo mađarske nacionalnosti, i trenutno je jedno od najrelevantnijih pozorišta kako u Srbiji, tako i u regionu. Svojom neobičnom pozorišnom poetikom i raznovrsnim repertoarom, uspeli su da ponovo privuku publiku u pozorište. Učestvovanjem na mnogobrojim festivalima, kao i igranje nekih od najvećih dela, kako mađarske i klasične literarture, kao i smeli eksperimentalni poduhvati, nešto su što Novosadsko pozorište i dalje čini aktuelnim i zanimljivim svim generacijama gledalaca. Među najuspešnije njihove predstave spada i Kosa Džeroma Ragnija ${ }^{11}$ i Džejmsa Radoa ${ }^{12}$. Takođe, komadi Edvarda Olbija, Artura Milera i Judžina O'Nila nisu nepoznanica ovom teatru, gde su neke drame, poput Ko se boji Virdžinije Vulf izvedene prvi put na novosadskoj sceni. ${ }^{13}$

\section{3. Pozorište mladih}

Pozorište mladih je osnovano 1932. godine, kao Lutkarsko pozorište. Tokom Drugog svetskog rata pozorište nije radilo i pretrpelo je ogromnu materijalnu štetu. Posle rata menja ime u Vojvođansko pozorište lutaka, zatim u Gradsko pozorište lutaka, pa samo Pozorište lutaka, da bi 1968. godine postalo Pozorište mladih, koje je i prvo lutkarsko pozorište u Vojvodini i Srbiji. Dramska scena počinje sa radom 1991. godine. Naža-

11 Džerom Ragni (Pitsburg, 11. septembar 1935. - Pitsburg, 10. jul 1991. godine) američki glumac, pevač i tekstopisac. U saradnji sa Radoom napisao tekst za mjuzikl Kosa. Osvojili su Gremi za najbolji mjuzikl 1969. godine

12 Džejms Rado (Venis Bič, 23. januar 1932.) američki reditelj, glumac, dramaturg i kompozitor. Sa Ragnijem napisao tekst za mjuzikl Kosa.

13 Vilovac, J. (05. novembar 1964) Sasvim svesno izazivanje. Dnevnik, str. 9. 
lost, do sada nije bilo postavki američkih pisaca na sceni Pozorišta mladih, osim gostovanja, među kojima je poslednje bilo izvođenje drame Tenesi Vilijamsa Tramvaj zvani želja, Zvezdara teatra iz Beograda.

\section{IZVOĐENJA AMERIČKIH AUTORA U NOVOM SADU}

\section{1 Drame Judžin O’Nila}

\section{7. godina}

Prva izvedena drama Judžina O’Nila je bila Mesečina za nesrećne 1967. godine, u Srpskom narodnom pozorištu, u režiji Dimitrija Đurkovića ${ }^{14}$. Predstava je bila prikazana dvadeset i dva puta, a videlo ju je ukupno 7.675 gledaoca. O’Nilov komad je bio pogodan zbog malog broja uloga, ali i priče koja je mogla lako komunicirati sa publikom. Likovi Judžinovih komada su savremeni ljudi sa kojima se gledaoci mogu poistoveti. Iako je odluka reditelja Dimitrija Đurkovića da predstavu skrati sa pet sati na dva i po sata igranja ${ }^{15}$ negativno dočekana od kritike, čini se da to publici nije smetalo. Novina u igranju je bio naturalistički pristup koji je šokirao publiku naviknutu na dotadašnji realizam na sceni. Uprkos svim promenama, reditelj je ostao veran tekstu, što je rezultiralo odličnom predstavom sa nekoliko gostovanja (Rumunija, Jugoslovensko dramsko pozorište, Sombor) i nagradama glavnim glumcima. Mesečina za nesrećne je bila slika ljudi koji na žestok način žive i vole, mešavina drame i tragedije i na kraju porodična drama koju novosadska publika i danas voli da gleda.

1995. godina

Drugo i poslednje izvođenje nekog komada Judžina O’Nila u Srpskom narodnom pozorištu bilo je 1995. godine, opet sa dramom Mesečina za nesrećne. Ovog puta, za režiju je bila zadužena Vida Ognjenovićc ${ }^{16}$. Predstava je izvedena petnaest puta, od toga jednom na gostovanju i ukupno ju je videlo 2.335 gledalaca. 1995. godine Srpsko narodno pozorište se vraća ne samo domaćoj, nego i svetskoj klasici, a Judžin O’Nil je bio

14 Kujundžić, M. (27. novembar 1967). Zakon dvojnih naravi. Dnevnik, str. 7.

15 Isto, str. 7.

16 Popov, N. (14. januar 1995). Povratak literarnom teatru. Dnevnik, str. 9. 
pravi izbor. Iako u režijskom smislu predstava trpi neke promene, kao što su skraćivanje, ukidanje osećaja krivice kod likova, kako bi se izbegla melodramatika, cela igra je svedena, sama režiserka je tvrdila da je prva verzija iz 1967. godine - surovija ${ }^{17}$. Dopisivanjem kraja, predstava pada u opasnost da postane melodrama, ali preciznom i odmerenom režijom, sa istančanim promenama emocija između likova, dobijena je zadovoljavajuća predstava bez sladunjavosti.

1996. godina

Dugo putovanje u noć imalo je svoju premijeru 1996. godine u Novosadskom pozorištu. Režirao ju je Milan Belegišanin ${ }^{18}$. Predstava je prikazana samo tri puta, i videlo ju je 125 gledalaca.

Belegišanin je adaptirao klasično delo sa pričom koja može da se primeni i na novosadskim pozornicama. Reditelj ovu dramu posvećuje svim nesrećnim porodicama, a samo Dugo putovanje u noć je metafora trenutnog života. Štrihujući ${ }^{19}$ tekst i svodeći ga na trećinu prvobitno napisanog, u toku predstave ima više slabih mesta što su kritičari dobro primetili, jer momentalno uvođenje priče u sukob i suštinu dela, izbacuje publiku iz predstave i narušava intenzitet radnje.

\section{II.2. Tenesi Vilijams}

1952. godina

Prvi komad Tenesi Vilijamsa izveden je u Novom Sadu 1952. godine. ${ }^{20} \mathrm{U}$ pitanju je njegov komad kojim je stekao slavu i popularnost, Staklena menažerija. Devet godina posle premijere u SAD, drama je ugledala svetlost dana i u Novom Sadu. Komad je režirao Aleksandar Ognjanovićc ${ }^{1}$, a predstava je izvedena devet puta i pogledalo ju je 2.550 gledalaca. Tadašnji problem sa postavkom komada je bilo pitanje da li dramska dela Tenesi Vilijamsa mogu oživeti na našim pozornicama? S obzirom da će

17 Kujundžić,M. (1994/1995). Očajni, nemoćni, ukleti, Pozorište, 3/4/5, str. 12.

18 Popov, N. (20. jun 1996). Premijera Judžina O’Nila. Dnevnik, str.11

19 Nem. (Strich - potez, crta, linija) - precrtavanje, izbacivanje teksta iz pozorišnog komada; skraćivanje pozorišnog dela.

20 Vidi: https://www.snp.org.rs/enciklopedija/?p=15695: Strana posećena, 10. maja 2018. godine.

21 Isto. 
do sledeće premijere proći šest godina, kao i veoma mali broj izvedenih predstava, čini se da novosadska publika u tom trenutku nije bila spremna za neprilagođene pojedince iz daleke Amerike.

1958. godina

Druga Vilijamsova predstava je izvedena 1958. godine, Tetovirana ruža. Iako je izvedena sedam godina kasnije na našim scenama nego u Americi, ovaj komad je jedan od primera koliko je Srpsko narodno pozorište bilo otvorenije prema stranim piscima, kao i dramama koje nisu bile strogo poučnog karaktera. Ovaj komad je režirao Bora Hanuska ${ }^{22}$ i izveden je osamnaest puta pred publikom, pred ukupno 8.093 gledaoca. Kritika je Tetoviranu ružu okarakterisala kao zadovoljavajuću, živu predstavu sa uverljivim ženskim likovima, što se nažalost ne može reći i za glumca koji je tumačio Alvara ${ }^{23}$.

1991. godina

Drugi put na repertoaru Srpskog narodnog pozorišta dolazi Staklena menažerija, koja i premijerno otvara 130. sezonu u pozorištu. Ovaj put reditelj je Bogdan Ruškuc ${ }^{24}$, koji bira Staklenu menažeriju, koja se uklapa u ciklus porodičnih drama, što se pokazalo kao tematika koja godi publici. Ruškuc pravi osvrt na prvu verziju, ali radikalno skraćuje tekst kako ne bi došlo do zamora i dosade među publikom. Iako ima dosta štrihovanja, ostaje veran Vilijamsovom tekstu i melodrami. Kako kritika primećuje, muški likovi nose priču, dok su ženski ostali nerazvijeni i slabi. Predstava jeste ispunila određene standarde, ali nije bila vrhunskog kvaliteta. Najveće pitanje, koje su kritičari postavljali je, šta Tenesi Vilijams ima da ponudi posle četiri decenije? Odgovor je, uvek aktuelna tema u koju mogu da se užive i glumci i publika. Cilj postavke ovog komada je da se pozorišna publika vrati u pozorište. Iako je melodrama više i bolje prihvaćena u Americi nego u Evropi, ovakvi komadi, posebno tokom ratnih godina su budili čežnju i nadu za mir.

22 Vilovac, J. (02. novembar 1958), ,Tetovirana ruža“ Tenesi Vilijamsa. Dnevnik .

23 Stevan Šalajić.

24 Popov, N. (14. oktobar 1991) Dramski rimejk. Dnevnik, str. 14, i Putnik, R. (27. oktobar 1991) Trošni životi. Politika, str. 19. 
1998. godina

Ako izuzmemo gostovanja, poslednji put je neka drama Tenesi Vilijamsa izvedena pre 20 godina na novosadskim pozornicama. To je bila Mačka na usijanom limenom krovu, u režiji Ljuboslava Majere ${ }^{25}$. Predstava je izvedena sedamnaest puta, video ju je 5.471 gledalac. Majera navodi kako je ova predstava vapaj za ljubavlju, ali i večito pitanje, zašto su svi ti ljudi na okupu, zašto se drže veza koje ih unesrećuju?

\section{II.3. Artur Miler}

1970. godina

Prva premijera komada Artura Milera je bila 1970. godine. Predstavu Pogled s mosta je režirao Tibor Rakovski ${ }^{26}$, igrana je dvadeset i jedan put i videlo ju je 8.730 gledalaca. Oživljeni klasik, vraća publiku u 1955. godinu, kada je prvi put izvedena u Njujorku. Ova predstava unosi svežinu u pozorište i vraća nadu u povratak publike u salu, koja je polako počela da se osipa u prethodnom periodu usled nedostatka kvalitetnih sadržaja. Politika navodi da je Pogled s mosta jedna od najboljih predstava u sezoni. Razlog za to može biti rediteljevo insistiranje na realističkoj glumi, ali i uvođenjem filmskih elemenata na scenu. S druge strane tu je i tekst, koji je uvek vezan za sudbinu savremenog čoveka, što publika uvek rado prihvata.

\section{7. godina}

Drugi komad izveden u Srpskom narodnom pozorištu je Smrt trgovačkog putnika ${ }^{27}$, sedam godina posle drame Pogled s mosta. Ova drama, u režiji Dimitrija Đurkovića, nije dobro prošla ni kod kritike, ni kod publike, iako je izvedena trinaest puta i videlo ju je 4.490 gledalaca. Iako je Milerovo delo bilo aktuelno, jednoličan i usporen ritam predstave, te obilje emocija naspram hladnoće likova u drami Smrt trgovačkog putnika, ne izazivaju dobar prijem kod publike. Iako su neki elementi predstave, na

25 Pozorišni program Srpskog narodnog pozorišta za predstavu Mačka na usijanom limenom krovu u pozorišnoj arhivi SNP-a u Novom Sadu.

26 Ćirilov, J. (06. april 1971) Na starom koloseku. Politika, str. 11. i D. B. (03. april 1971) Tri večeri u tri pozorišta. Borba, str. 12.

27 Kujundžić, M. (20. februar 1977) Neuspeh na drumu života. Dnevnik, str. 16. 
primer scenografija, uspeli da oslikaju atmosferu, to ipak nije bilo dovoljno da popravi celokupan dojam o predstavi, koja je izneverila očekivanja.

1991. godina

Stvaranje sveta i ostale stvari je prikazana 1991. godine u Novosadskom pozorištu u saradnji sa Akademijom umetnosti. Predstava je izvedena pet puta, i videlo ju je 256 gledalaca. Režiser predstave, Gabor Pinter ${ }^{28}$ navodi kako je ovaj komad dvopolan, polazi od komičnih elemenata, a završava bratoubistvom.

1994. godina

Svi moji sinovi su otvorili sezonu 1994. godine u Novosadskom pozorištu. Režiser, Laslo Gergelj ${ }^{29}$, postavlja ovu predstavu zboga aktuelnosti teme u datom trenutku. Postavlja se pitanje šta je društvo napravilo od moralnog junaka? Iako je predstava odigrana dvadeset i dva puta, od toga pet puta na gostovanjima, videlo ju je samo 2.588 gledalaca.

\section{4. Edvard Olbi}

1964. godina

Prvi komad Edvarda Olbija izveden na pozornici Srpskog narodnog pozorišta bio je Ko se boji Virdžinije Vulf 1964. godine, iste godine kada je izvedena u Beogradu, a dve godine posle američke premijere. Reditelj, Dejan Mijač ${ }^{30}$, nije imao lak zadatak pred sobom. Tekst drame je fragmentaran i dugo traje, ali otklanjanjem leksičkih problema i nedoumica, Mijač publici otkriva Olbijeve likove i oživljava ih na sceni. Tim postupkom je nastala drama koja u sebi nosi elemente realizma, ekspresionizma i naturalizma. Najveća zamerka kritike je bila u tome da su tempo i ritam predstave neujednačeni.

1970. godina

Drugo izvođenje nekog teksta Edvarda Olbija bilo je 1970. godine u Srpskom narodnom pozorištu. Sve zbog bašte je režirao Želimir Oreško-

28 M.P. (14. mart 1991) Biblijski likovi. Dnevnik, str. 21.

29 Popov, N. (04. oktobar 1994) Početak sezone. Dnevnik, str. 9.

30 Vilovac, J. (05. novembar 1964) Sasvim svesno izazivanje. Dnevnik, str. 9. 
vić $^{31}$ i predstava je odigrana dvadeset i dva puta, od toga su bila četiri gostovanja, sve ukupno ju je videlo 8.471 gledalaca. Ovaj komad je otvorio sezonu, a postavljen je na novosadsku pozornicu dve godine posle američke premijere. Reditelj je ostao dosledan tekstu. što je rezultiralo dobro primljenom predstavom i pohvalama svim učesnicima.

1976. godina

Ko se boji Virdžinije Vulf prikazana je 1976. godine u Novosadskom pozorištu, četrnaest godina posle premijere u Sjedinjenim Američkim Državama. Predstava je izvedena dvadeset i sedam puta, od toga tri puta na gostovanjima. Ukupno ju je videlo 3.668 gledalaca. Kritika je pohvalila rad reditelja Tibora Vajde ${ }^{32}$, kao i glumce. Dobra gluma i mizanscen su načinili od ovog komada živu stvar koja je privukla i zaintrigirala publiku.

1980. godina

Drugo izvođenje komada Sve zbog bašte, ovog puta na daskama Novosadskog pozorišta desilo se deset godina kasnije, 1980. godine. Režiser Tibor Vajda odluku da se ova predstava postavi, nalazi u tome da je to komad sa aktuelnom temom, tekst se ne mora modernizovati pošto je blizak današnjem vremenu. Predstava je izvedena devet puta, od toga jednom na gostovanju, sa ukupnim brojem od 1.608 gledalaca. Zamerka kritike ide na račun glumice (Irena Abraham) koja nije uspela da nađe zajednički jezik za glavnim glumcem (Karolj Fišer). Predstava je ostavila solidan utisak zbog svoje aktuelnosti i pogleda na trenutne probleme.

1987. godina

Delikatna ravnoteža je imala svoju prvu premijeru 1987. godine u Novosadskom pozorištu, dvadeset i jednu godinu posle svog nastanka. Režiser Mihalj Virag ${ }^{33}$ navodi da je ovo drama ljudskog očaja i opaka satira savremenog društva $i$ života. Nažalost, kritički prikaz ove predstave nije dostpan tako da ne znamo razlog zbog čega je izvedena samo dva puta.

31 Kujundžić, M. (15. oktobar 1970) Stravično veče lepotice dana. Dnevnik, str. 11.

32 Aladić, J. (20. februar 1976) Sjajna igra jedne glumice. Dnevnik, str. 15.

33 Savković, N. (25. jun 1987) Strah od promene. Dnevnik, str. 11. 
1997. godina

Većina predstava postavljenih tokom devedesetih godina su bile kratkog veka, pa tako i Zoo priča. Scenski i tekstualno jednostavan komad koji je sa svojom temom bio aktuelan 1959. godine kada je napisan, 1997. kada je izvođen, ali i danas. Ova predstava je nastala u saradnji Srpskog narodnog pozorišta i Pozorišta Promena, a režirao ju je Nikola Vukčevićc ${ }^{34}$. Predstava je izvedena jedanaest puta i videlo ju je 320 gledlaca.

\section{5. Sem Šepard}

Jedina predstava Sema Šeparda je izvedena 1990. godine u Srpskom narodnom pozorištu. Komad Lud od ljubavi režirao je Egon Savin ${ }^{35}$, a prikazana je četiri puta, sa ukupnim brojem od 994 gledaoca. Kako se reditelj izjasnio, ovo je predstava koja se izražava preko glumaca, a najveći problem je bio težak tekst i bojazan od upadanja u kalup žanra, što bi u ovom slučaju bila laka ljubavna melodramska priča, a to se htelo izbeći po svaku cenu kako bi se ostao veran originalnom tekstu.

\section{6. Dejvid Memet}

Od pomenutih pisaca, Dejvid Mamet je jedini koji je još živ i stvara. Uprkos tome, čini nam se, da u Novom Sadu dela ovog poznatog pisca nisu zaživela. Osim gostovanja pozorišta iz Beograda, sa čuvenom predstavom Čikaške perverzije, u Novom Sadu je prikazan samo jedan komad. U pitanju je predstava Bizon koji je odigrana 2013. godine, šest puta, koju je postavio Saveza dramskih umetnika Vojvodine, a režirao Miljan Vojnović $^{36}$. Nažalost, drugih informacija o ovoj predstavi nema.

34 Vidi: Pozorišni bilten Srpskog narodnog pozorišta iz arhive pozorišta.

35 Popov, N. (12. maj 1990) Ljubavna priča. Dnevnik, str. 14. i Krčmar, V (1990). Između melodioznosti, ostaviti emotivnost. Pozorište, LVII, 793-794.

36 Vidi: Pozorišni godišnjak iz arhive Srpskog narodnog pozorišta. 


\section{ZAKLJUČAK}

„Čudna je ta američka književnost.

U Evropi pisanje ne mora da bude obavezno korisno...

Američki pisci se uvek nadaju da će njihovi čitaoci izaći na ulicu i početi da urlaju kao sumanuti kako su srećni što žive, kako im je žena kurva ili kako će crći od žeđi.“"(Begbede, 2017: 9)

Period posle II svetskog rata obeležio je prodor savremenih američkih dramskih pisaca na evropsku scenu, tako i u područja bivše Jugoslavije. Judžin O’Nil je već spadao u klasiku, a njegovi naslednici, Tenesi Vilijams, Artur Miler i Edvard Olbi nastavljali su njegovim putem, prikazujući Ameriku i američki san u novom i oporom svetlu.

Sa izvođenjem Beketovog Čekajući Godoa ${ }^{37}$ u Beogradu, u Jugoslaviji se dopušta prodor modernog i avangardnog teatra na pozorišne daske, otvara se širok prostor za autore sa zapada, i počinje se ispisivati istorija novog načina igranja, tumačenja i pozorišnog izraza uopšte. Tu su među izabranima $\mathrm{i}$ autori američkog dramskog iskaza. To nam potvrđuje Jovan Hristić: „Oni su nam otkrivali jedno novo osećanje života i jedan novi ritam života. Kao da su došli iz nekog davno izgubljenog raja, njihove priče imale su jednostavne rečenice koje se ne ustručavaju od banalnosti, dijalog koji više podrazumeva, nego što otvoreno kaže, što nam je sve otkrivalo neki novi dodir sa osnovnim istinama života." (Vučetić, 2012: 261)

Prihvatanje američkih dramskih pisaca nije išlo glatko, ni znanje o Americi nije bilo veliko, te su režiseri saznali o tom dalekom kontinentu putem drama Tenesi Vilijamsa i Artura Milera. Repertoari beogradskih pozorišta - Beogradskog dramskog pozorišta, Jugoslovenskog dramskog pozorišta, Savremenog pozorišta i Ateljea 212, dokaz su da su vodeći američki pisci često i rado igrani i da su bili popularni među jugoslovenskom publikom $^{38}$.

Što se tiče igranja američkih dramskih pisaca u novosadskim pozorištima, Srpskog narodnog pozorišta, Novosadskog pozorišta i Pozorišta mladih, primetna je nešto drugačija percepcija njihovog dela kod kritike i publike; naime, za određene predstave može se reći da su doživele fijasko

37 Vidi: Vučetić, Radina. Koka-kola socijalizam. Beograd: Službeni glasnik, 2012.

38 Vidi: Vučetić, Radina. Koka-kola socijalizam. Beograd: Službeni glasnik, str. 267; 2012. 
kod publike, odnosno, kritike, neke kod obe strane, dok su retke predstave koje su se mogle oceniti kao pozorišni i kulturni događaji kod veoma zahtevne, i poprilično hladne novosadske pozorišne javnosti. Naravno, ovde možemo navesti i određeno pomanjkanje uslova za izvođenje određenih dramskih komada, neadekvatne režisere, glumačke podele, pogrešno pročitane tekstove, lošu organizaciju predstave, a ponekad i rad na komadu koji ne korespondira sa trenutnim ukusom publike.

\section{Literatura:}

\section{a. Studije}

Begbede, F. (2017). Predgovor. U: Miler, A. (2017). Rakova obratnica. Beograd: Laguna Bigsby, C. W. E . (2004). Modern American Drama 1945-2000. Cambridge: Cambridge University Press

Ćirilov, J. (prir.). (2002). Pre i posle Kose. Savremena američka drama. Beograd: Zepter Book World

Grant, N. (2006). Istorija pozorišta. Beograd: Zavod za udžbenike

Hristić, J. (2017). Dugo traganje za pozorištem. Zrenjanin: Gradska narodna biblioteka Žarko Zrenjanin

Pozorište mladih: http://pozoristemladih.co.rs/ [01.06.2018]

Srpsko narodno pozorište: https://www.snp.org.rs/enciklopedija/ [01.06.2018]

Vilijams, T. (2002a). Tramvaj zavni želja. Beograd: NNK International

(2002b). Tetovirana ruža. Beograd: NNK International

(2002c). Mačka na usijnom limenom krovu. NNK International

Vučetić, R. (2012). Koka-kola socijalizam. Amerikanizacija jugoslovenske popularne kulture šezdesetih godina XX veka. Beograd: Službeni glasnik

b. Časopisi, dnevne novine

Dnevnik, Novi Sad: godišta 1958, 1967, 1964, 1968, 1970, 1971, 1976, 1977 , 1980, 1987, 1990, 1991, 1994, 1995, 1996

Politika, Beograd: godišta: 1967, 1968, 1970, 1971, 1977, 1991

Politika Ekspres, Beograd, godišta: 1967, 1968, 1970

Borba, Beograd, godišta: 1967, 1971

Somborske novine, Sombor, godišta: 1968

Večernje novosti, Beograd, godišta: 1968 
Misao, Novi Sad, godišta: 1991

Stav, Novi Sad, godišta: 1991

Pozorište, Novi Sad, godišta: 1991/92, 1994/95

Stanislava D. Radosavljević

\title{
CONTEMPORARY AMERICAN DRAMA ON NOVI SAD'S SCENES FROM 1958 TO 2017
}

\begin{abstract}
Summary
In our work, we are going to look into the period from 1958, when the first drama was performed (The Rose Tattoo Tennessee Williams), up until 2017. We are going to explore American drama on Novi Sad's stages. The focus is goin to be on two Novi Sad's theaters, the Serbian National Theater and the Novi Sad Theater, while the Youth Theater won't be receving much attention, apart from the guestings that will be mentioned in this paper. Of all modern American writers, works from these playwrights were performed most commonly: Eugene O'Neill, Tennessee Williams, Arthur Miller, Sam Shepard, Edward Albee and David Mamet. The main goal of this research will be the reception of their works to the Novi Sad's audience. We will show when, how and under what circumstances were the pieces of the mentioned writers shown and what kind of influence they had on the audience, why some drama is still popular, and why others are no longer being shown. In the production of this work we will use theater annuals, newspaper articles and featured reviews, theater annals and archives of Sterija Awards.
\end{abstract}

Key words: American drama, Novi Sad's theaters, Eugene O'Neill, Tennessee Williams, Arthur Miller, Sam Shepard, Edward Albee and David Mamet 